\title{
Fabrication of high-resolution conductive patterns on a thermally imprinted polyetherimide film by the capillary flow of conductive ink
}

\author{
Takashi Kurose $^{1}$ (D) $\cdot$ Hiroto Shishido ${ }^{2} \cdot$ Akira Ishigami $^{2,3} \cdot$ Akihiko Nemoto $^{3} \cdot$ Hiroshi $^{\text {Ito }}{ }^{1,2,3}$
}

Received: 4 January 2020 / Accepted: 6 January 2020 / Published online: 13 January 2020

(C) The Author(s) 2020

\begin{abstract}
We developed herein a simple and economical high-resolution wiring process on a plastic substrate. High-resolution conductive patterns on the PEI film was fabricated by utilizing the thermal imprint technology and the capillary flow of the conductive ink. An amorphous thermoplastic polyetherimide (PEI) film was thermally imprinted with a metal mold having line $(8 \mu \mathrm{m}) /$ space $(12 \mu \mathrm{m})$ structures. The effects of the imprint temperature, melting time, and imprint pressure on the PEI film transferability were investigated. A higher replication ratio was obtained when the molding temperature was higher, the melting time was longer, the imprint pressure was higher, and the mold structure height was lower. The mold structures were almost perfectly transferred on the PEI film surface at a molding temperature of $285{ }^{\circ} \mathrm{C}$, a melting time of $3.0 \mathrm{~min}$, and a molding pressure of 1.0 MPa. Two different wiring processes, namely, spin coating and capillary flowing of Ag ink onto the imprinted PEI film, were conducted. For the spin-coating wiring process, the Ag ink existed not only inside the grooves but also on the convex area as the residual layer, regardless of rotational speed and time. For the capillary flowing wiring process, when the Ag ink contacted the edge of the imprinted pattern on the PEI film, it spontaneously flowed toward the wiring direction. Only the concave grooves were selectively filled with Ag ink, and the residual layer was not observed. The fabricated wiring conformed to Ohm's law, with an electric resistivity of $42 \times 10^{-8} \Omega \mathrm{m}$.
\end{abstract}

\section{Introduction}

Flexible printed circuit (FPC) boards are widely used in various electronic devices. Accordingly, a technology for a higher-resolution pattern on the FPC is required to further miniaturize electronic devices. The current conventional fabrication process represented by the subtractive method using a copper-clad laminate is limited in terms of highresolution patterns caused by the over-etching of copper due to the wet etching process. The minimum line width in the current subtractive method might be approximately $30 \mu \mathrm{m}$. Other serious disadvantages of the current

Hiroshi Ito

ihiroshi@yz.yamagata-u.ac.jp

1 Research Center for GREEN Materials and Advanced Processing, Yamagata University, 4-3-16 Jonan, Yonezawa, Yamagata 992-8510, Japan

2 Graduate School of Organic Material Science, Yamagata University, 4-3-16 Jonan, Yonezawa, Yamagata 992-8510, Japan

3 Faculty of Engineering, Yamagata University, 4-3-16 Jonan, Yonezawa, Yamagata 992-8510, Japan technology are the complexity of the multiple-step process, including photolithography and wet etching processes with chemicals leading to hazardous waste, which consequently result in an expensive capital investment cost.

For the abovementioned reasons, research on printed electronic technologies [e.g., inkjet printing (Leenen et al. 2009; Arias et al. 2010) and screen printing (Faddoul et al. 2012; Jiang et al. 2016)] to directly produce a conductive pattern onto a flexible plastic film is being considerably performed. Inkjet printing is one of the most commonly used techniques for producing high-resolution conductive patterns because of its simplicity and minimal waste of materials (Kawase et al. 2003; Kang et al. 2012). However, some challenges still exist. The resolution of the inkjetprinted patterns is influenced by the nozzle size. Moreover, the reduction of the nozzle size is limited because of the ink-clogging problem. The ink spreading on the plastic film substrate can also degrade the pattern quality. As a solution to this problem, the inkjet technique printing onto a patterned surface with a wettability contrast having hydrophilic and hydrophobic regions predefined on the substrate is proposed (Sirringhaus et al. 2000; Wang et al. 2004; Sele et al. 2005; Kawahara et al. 2013). The printed ink is 
repelled from the hydrophobic region and selectively placed on the hydrophilic region. However, most of the previous works used complex and expensive processes, such as photolithography, electron-beam lithography, and plasma treatment, to form a surface wettability contrast.

A new surface wettability patterning technique was reported (Lee et al. 2016). The patterned surface with a wettability contrast was relatively simply achieved with the help of soft lithography processes, in which the surface was micro-structured and chemically modified using nanoimprint lithography (NIL) (Chou et al. 1995; Hendriks et al. 2008 ) and microcontact printing $(\mu \mathrm{CP})$ (Michel et al. 2001). Although a high-resolution printed line array with a line width and a gap distance of several micrometers was fabricated by this method, the process still needed a liftoff of the hydrophobic fluorocarbon (FC) layer after the inkjet process by using wet chemistry to remove the ink stains from the FC layer.

We propose herein a simple and economical high-resolution wiring process that utilizes the thermal imprint technology of a thermoplastic film (Hernández et al. 2017; Muanchan et al. 2017) and the capillary flowing of conductive ink. Figure 1 shows the process concept. A metal mold with a microscale concave and convex pattern was machined. The metal mold pattern was transferred onto the thermoplastic polyetherimide (PEI) film surface through the thermal imprint technology. Conductive $\mathrm{Ag}$ ink was applied to the imprinted PEI film, and only the concave grooves were selectively filled with the Ag ink. The PEI film with the Ag ink pattern was heat-treated such that the Ag particles were sintered to improve the electric conductivity and adhesion between the PEI film substrate and the Ag ink.

This research aims to confirm the feasibility of the process concept for a high-resolution conductive pattern. The effects of the thermal imprint process condition on the PEI transferability and the influence of different Ag ink application methods on the wiring quality were investigated.

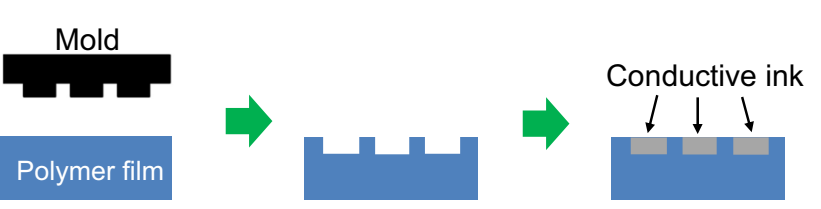

(a) Thermal imprint

(b) Capillary flow of ink

Fig. 1 Fabrication process of a high resolution conductive pattern

\section{Experimental}

\subsection{Thermal imprint process}

An amorphous thermoplastic polyetherimide (PEI) film (film thickness: $115 \mu \mathrm{m}, \mathrm{Tg}=225^{\circ} \mathrm{C}$, SUPERIO ${ }^{\mathrm{TM}} \mathrm{UT}$, Mitsubishi Chemical Holdings Group) was used as the substrate for a flexible print circuit board. An aluminum (Al) mold was used for the thermal imprint process. Figure 2 and Table 1 show the mold surface dimensions. The $\mathrm{Al}$ mold had three types of line/space structures on the mold surface. Only the height was different. The line width, space width, and pitch length were $8 \mu \mathrm{m}, 12 \mu \mathrm{m}$, and $20 \mu \mathrm{m}$, respectively. The line/space structures were machined by an ultra-precision nanomachine (ROBONANO $\alpha$-oiB, FANUC Corp.) with a diamond tool.

Table 2 summarizes the thermal imprint conditions. The $\mathrm{Al}$ mold and the PEI film were placed on a thermal imprint machine (vacuum hot press, Izumi Tech., Japan) under various temperatures from 245 to $295^{\circ} \mathrm{C}$. After heating the mold together with the PEI film for various melting times from 1.0 to $3.0 \mathrm{~min}$, the pressure from 0.5 to $1.0 \mathrm{MPa}$ was applied for $1.0 \mathrm{~min}$ using the thermal imprint machine. After applying the pressure, the film together with the mold was cooled under a cooling press machine.

\subsection{Wiring process}

Two different wiring processes, namely, spin coating and capillary flowing of the $\mathrm{Ag}$ ink onto the PEI film, were conducted. The PEI film imprinted by a mold with a $10-\mu \mathrm{m}$-hight structure was used for the wiring process. The commercially available Ag nanoparticle ink (NPS-JL, Harima Chemicals Group, Inc.) consisting of 55 wt.\% Ag particle (average particle diameter: $7 \mathrm{~nm}$ ) and a tetradecane solvent, including naphthene, were applied. The viscosity of the Ag ink was $11 \mathrm{mPa} \cdot \mathrm{s}$ (catalog value). The contact angle between the PEI flat film and the Ag ink was $19.5^{\circ}$. The contact angle was measured by a contact angle meter (DM 500, Kyowa Interface Science, Japan). For the spin-coating process, the Ag ink $(20 \mu \mathrm{l})$ was dropped by a conventional micropipette onto the center of the imprinted PEI film surface during the film rotation. Various constant (a)

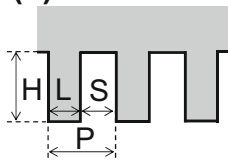

(b)

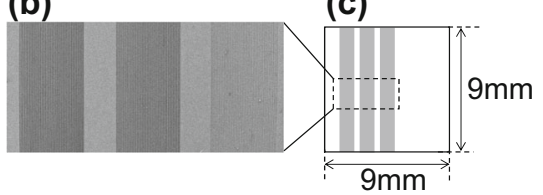

Fig. 2 Structure and dimension on the mold surface. a Cross section image on a mold surface. $\mathbf{b}$ SEM image of a mold surface. $\mathbf{c}$ Top view image of a mold surface side 
Table 1 Specification of mold structures

\begin{tabular}{lllll}
\hline Mold structural no & 1 & 2 & 3 \\
\hline $\mathrm{H}$ & Height $(\mu \mathrm{m})$ & 10 & 20 & 30 \\
$\mathrm{~L}$ & Line width $(\mu \mathrm{m})$ & & 8 & \\
$\mathrm{~S}$ & Space width $(\mu \mathrm{m})$ & & 12 & \\
$\mathrm{H} / \mathrm{S}$ & Aspect ratio $(-)$ & 0.83 & 1.67 & 2.5 \\
$\mathrm{P}$ & Pitch length $(\mu \mathrm{m})$ & & 20 & \\
& Pitch number & & 50 &
\end{tabular}

Table 2 Thermal imprint condition

\begin{tabular}{ll}
\hline Temperature $\left({ }^{\circ} \mathrm{C}\right)$ & $245,255,265,275,285,295$ \\
Melting time $(\mathrm{min})$ & $1,2,3$ \\
Pressure $(\mathrm{MPa})$ & $0.5,0.75,1$ \\
Pressing time $(\mathrm{min})$ & 1 \\
\hline
\end{tabular}

rotational speeds from 500 to $3000 \mathrm{rpm}$ were conducted for 10 or $60 \mathrm{~s}$. For the capillary flowing process, the Ag ink that adhered to a stainless needle (needle tip diameter: $0.36 \mathrm{~mm}$ ) contacted the edge of the imprinted line/space pattern on the PEI film. The contacted Ag ink spontaneously filled the grooves. The PEI film was heat-treated under $180{ }^{\circ} \mathrm{C}$ for $60 \mathrm{~min}$ to evaporate the solvent and sinter Ag particles.

\subsection{Evaluation}

The transferability of the thermal imprint of the PEI film was evaluated using the replication ratio defined as follows:

$\mathrm{R}_{\mathrm{A}}=\left(\mathrm{S}_{\mathrm{i}} / \mathrm{S}_{\mathrm{m}}\right) \times 100$

$\mathrm{R}_{\mathrm{A}}$ is the replication ratio (\%); $\mathrm{S}_{\mathrm{i}}$ is the section area of the imprinted film surface structure; and $\mathrm{S}_{\mathrm{m}}$ is the section area of the mold surface structure. The section areas were measured by a 3D optical profiler (NewView 8300, Zygo). The average value in the three locations of the imprinted film was then estimated.

The cross section of the Ag wiring on the PEI film was observed after making a fracture section by applying impact with a knife under a cryogenic temperature with liquid nitrogen. The observation was conducted by a 3D laser measuring microscope (LEXT OLS4000, Olympus Corp.). The section area of the $\mathrm{Ag}$ wiring was measured. The total section area of the wiring was then estimated. The film surface from the top view was also observed. The Ag ink was observed by a scanning electron microscope (SEM) (JOEL, JSM-7600FA) to confirm the Ag particle formation after the heat treatment.
The electric resistance was measured by four terminal methods with a semiconductor parameter analyzer (Keithley 4200-scs, Tektronix Inc.). Four electrodes across 50 wirings were formed using conductive adhesion (DOTITE D-550, Fujikura Kasei Co., Ltd.). The electric resistivity was estimated by the following equation:

$\rho=\frac{R A}{l}$

Here, $\rho$ is resistivity, $R$ is resistance, $A$ is the total section area of the 50 wirings, and $l$ is the distance between two inner electrodes $(l=3.3 \mathrm{~mm})$.

\section{Results and discussion}

\subsection{Thermal imprint process}

Figure 3 shows the effect of the molding temperatures in the thermal imprint process on the replication ratio (molding pressure and melting time: $1.0 \mathrm{MPa}$ and $3.0 \mathrm{~min}$, respectively). A higher replication ratio was obtained as the molding temperature became higher. Accordingly, the PEI modulus decreased as the molding temperature increased. In addition, the PEI can be largely deformed at a higher temperature. Figure 4 shows the effect of the melting time on the replication ratio (molding temperature and molding pressure: $285^{\circ} \mathrm{C}$ and $1.0 \mathrm{MPa}$, respectively). The longer melting time led to a higher replication ratio. The temperature of the film and the mold was sufficiently increased during this melting time; hence, a higher replication ratio was obtained. Figure 5 illustrates the effect of the molding pressure on the replication ratio (molding temperature and melting time: $285^{\circ} \mathrm{C}$ and $3.0 \mathrm{~min}$, respectively). A higher molding pressure resulted in a higher replication ratio. Higher stress will be applied to the PEI film by a higher imprinting pressure; therefore, the PEI would be largely deformed.

The mold structures were almost perfectly transferred on the PEI film surface in the molding temperature of $285{ }^{\circ} \mathrm{C}$,

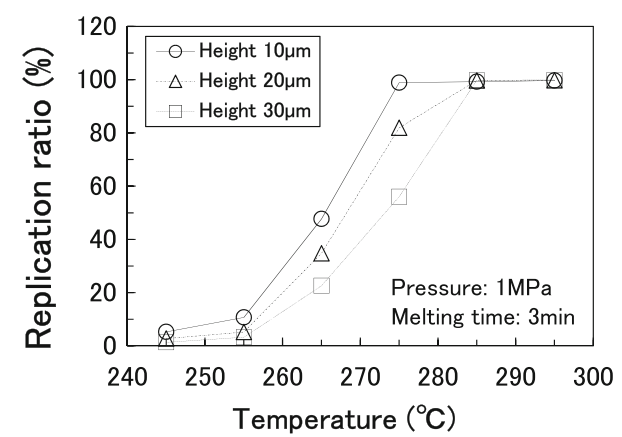

Fig. 3 Replication ratio imprinted with various mold structures and at various temperature 


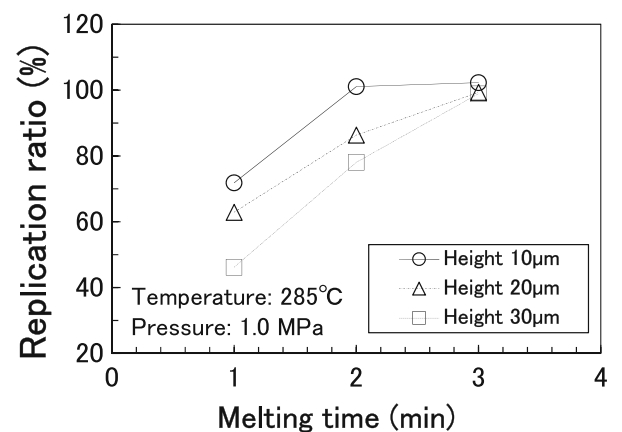

Fig. 4 Replication ratio imprinted with various mold structures and at melting time

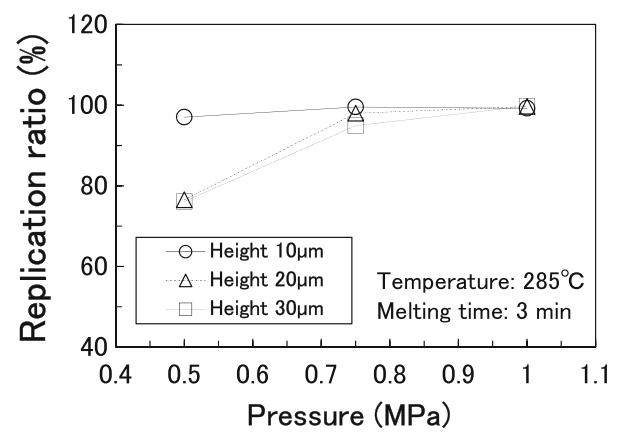

Fig. 5 Replication ratio imprinted with various mold structures and at various pressure

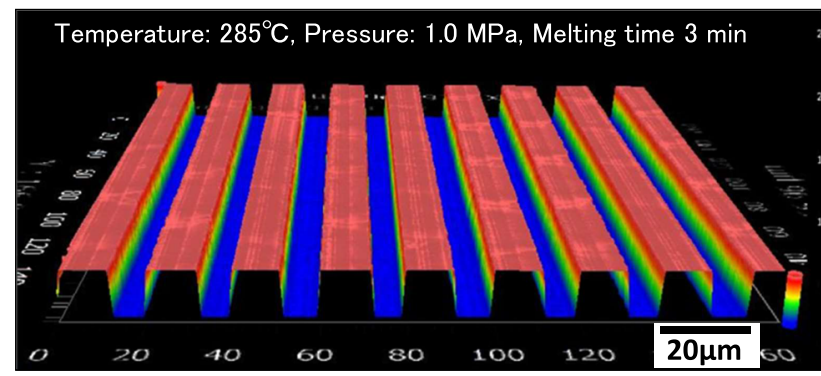

Fig. 6 Imprinted structure observed by a 3D optical profiler (mold height $30 \mu \mathrm{m}$, imprint temperature $285^{\circ} \mathrm{C}$, pressure $1.0 \mathrm{MPa}$, melting time $3 \mathrm{~min}$ ) a melting time of $3.0 \mathrm{~min}$, and a molding pressure of 1.0 MPa. Figure 6 shows the thermally imprinted PEI film surface observed by the 3D optical profiler, which was produced in the abovementioned process condition. The mold height was $10 \mu \mathrm{m}$. This process condition was selected to prepare the samples for the wiring process.

\subsection{Wiring process}

Figure 7 exhibits the cross section of the samples after spin-coating the Ag ink. Regardless of the rotational speed and time, the Ag ink existed not only inside the grooves but also on the convex area as a residual layer. The amount of the residual $\mathrm{Ag}$ ink layer on the convex area might be reduced by increasing the rotational speed and time. The conductive $\mathrm{Ag}$ ink existed both inside the grooves and on the convex area; therefore, eliminating the risk of a short circuit would be difficult, and the spin-coating process would not be applicable to the wiring process in this research.

Figure 8 shows the top view of the film sample after the capillary flowing wiring process. Microscope observation indicated that when the Ag ink contacted the edge of the imprinted pattern on the PEI film, it spontaneously flowed toward the wiring direction. Figure 8 illustrates a clear contrast between the PEI material and the Ag ink over a wide range. The Ag ink will be selectively filled either inside the grooves or on the convex area in the PEI film. Figure 9 shows the cross section of the sample after the capillary flowing wiring process. The section observed by the 3D laser microscope revealed that the Ag ink existed only inside the grooves, not on the convex area. The observation in Figs. 8 and 9 denoted that only the concave grooves were selectively filled with the $\mathrm{Ag}$ ink, and no residual layer, which might result in a short circuit, existed. Although the shape of the grooves after the thermal imprint should be rectangular, the shape observed by the 3D laser microscope differed from the rectangle in Fig. 9. This can be attributed to the structure being deformed when the fracture surface was prepared or the structure recovered
Fig. 7 Cross section of films after spin coating by silver ink. a $500 \mathrm{rpm}$ for $10 \mathrm{~s}$, b $500 \mathrm{rpm}$ for $60 \mathrm{~s}$, c $3000 \mathrm{rpm}$ for $10 \mathrm{~s}$, and d $3000 \mathrm{rpm}$ for $60 \mathrm{~s}$
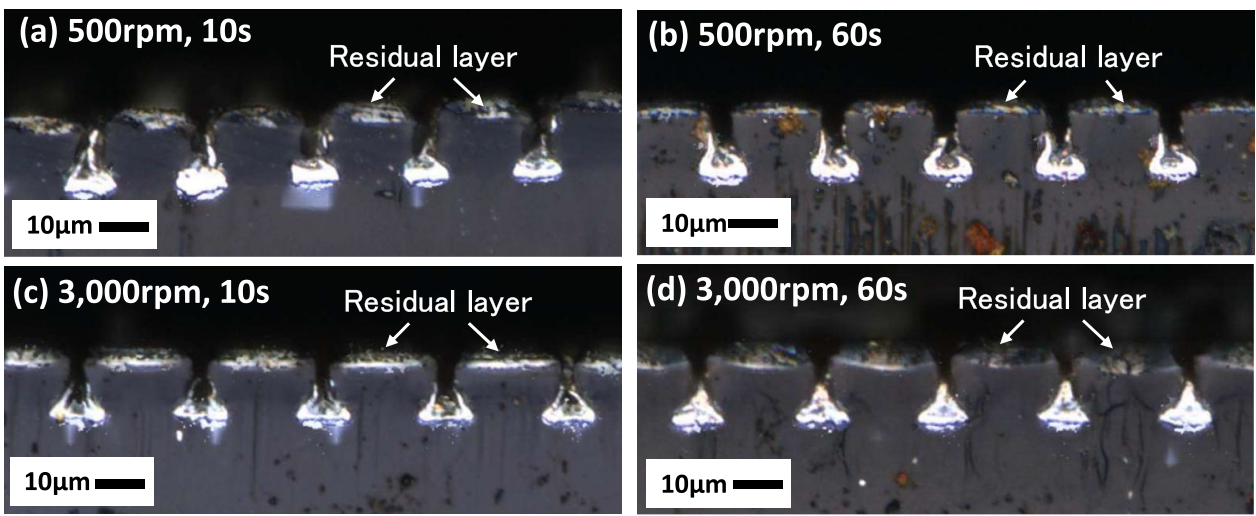


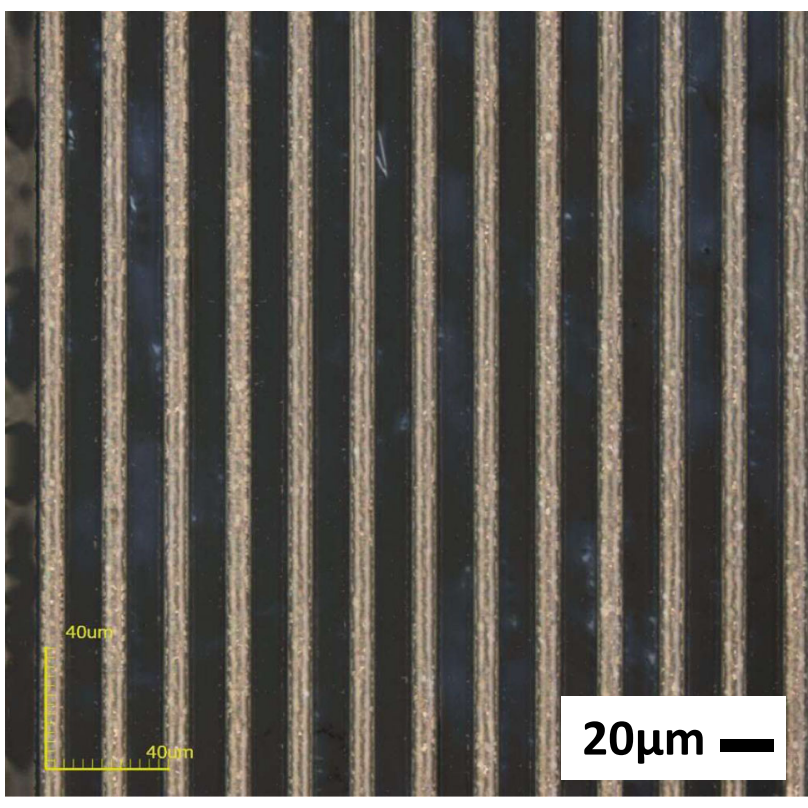

Fig. 8 Top view of a film after silver ink was applied

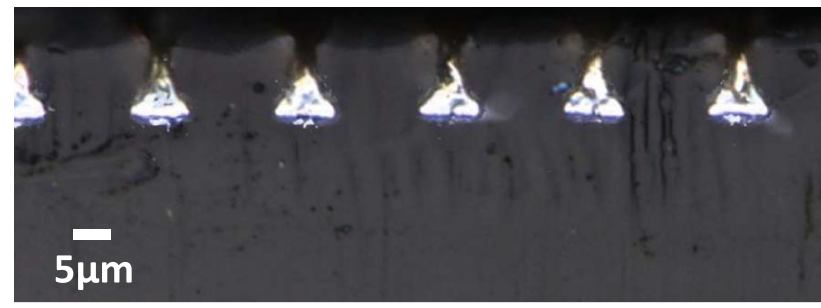

Fig. 9 Cross section of a film after silver ink was applied

during the heat treatment for $\mathrm{Ag}$ sintering at $180{ }^{\circ} \mathrm{C}$ for $60 \mathrm{~min}$. Figure 10 shows the $\mathrm{Ag}$ particles inside the grooves on the PEI film by SEM. Ag particles of approximately $100-\mathrm{nm}$ diameter were observed, and the particles appeared to be bound. The primary diameter of the $\mathrm{Ag}$ particles based on the catalog value was $7 \mathrm{~nm}$. The sintering of the Ag particles would be assumed to proceed during the heat treatment at $180{ }^{\circ} \mathrm{C}$ for $60 \mathrm{~min}$.

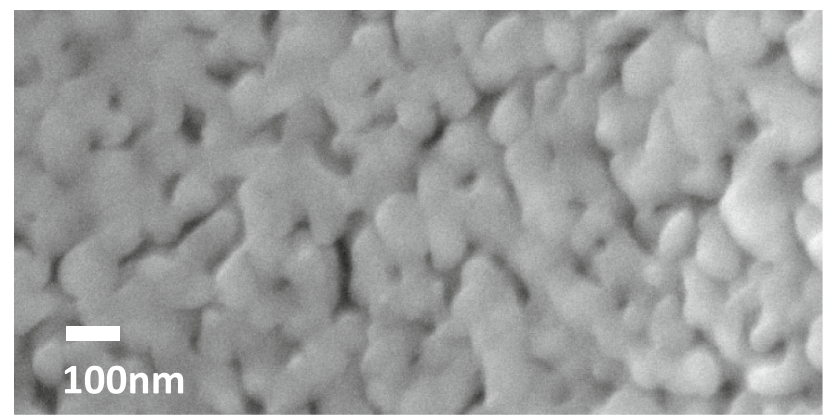

Fig. 10 SEM image of silver ink after heat treatment at $180{ }^{\circ} \mathrm{C}$ for $60 \mathrm{~min}$

\subsection{Electrical property of the wiring}

The electric resistance of the wiring produced by the capillary flowing process was measured. The current and the voltage showed a proportional relationship through the origin, which conformed to Ohm's law. The electric resistivity was estimated according to Eq. (2). Table 3 summarizes the calculation condition and results. The electric resistivity was $42 \times 10^{-8} \Omega \mathrm{m}$. High-resolution conductive patterns on the thermally imprinted polyetherimide film can be fabricated by the capillary flow of the conductive ink. In assumption, the resistivity was lower than that of bulk $\mathrm{Ag}\left(1.6 \times 10^{-8} \Omega \mathrm{m}\right)$ because the wirings were formed by the particles and the voids existing in the wiring. Another reason for this result could be the insufficient contact between the wiring and the conductive adhesion for the measurements. Ag ink existed inside the narrow concave shape of the PEI film; thus, the contact of the conductive adhesion to the wiring was not sufficient.

\section{Conclusions}

This study proposed a simple and economical high-resolution wiring process utilizing the thermal imprint technology of a thermoplastic film and the capillary flowing of the conductive ink. The feasibility of the process concept was also confirmed.

The effects of the thermal imprint process condition on the PEI film transferability were investigated. A higher replication ratio was obtained in all the mold structures when the molding temperature was higher, the melting time was longer, and the imprint pressure was higher. The mold structures were almost perfectly transferred on the PEI film surface in a molding temperature of $285^{\circ} \mathrm{C}$, a melting time of $3.0 \mathrm{~min}$, and a molding pressure of 1.0 MPa.

Two different wiring processes, namely, spin coating and capillary flowing of the Ag ink onto the PEI film, were conducted herein. For the spin-coating wiring process, regardless of the rotational speed and time, the Ag ink existed both inside the grooves and on the convex area of the PEI film as the residual layer. The spin-coating process was not applicable to the wiring process herein. Only the concave groove was selectively filled with the Ag ink, and no residual layer existed for the capillary flowing wiring process. The fabricated wiring conformed to Ohm's law, and the electric resistivity was $42 \times 10^{-8} \Omega \mathrm{m}$. 
Table 3 Measurement condition and results of electric properties

\begin{tabular}{llll}
\hline Distance of proves $(\mathrm{mm})$ & Total cross section area of wires $\left(\mathrm{m}^{2}\right)$ & Resistance $(\Omega)$ & Resistivity $(\Omega \mathrm{m})$ \\
\hline 3.3 & $9.8 \times 10^{-6}$ & 2.8 & $42 \times 10^{-8}$ \\
\hline
\end{tabular}

Acknowledgments We greatly acknowledge partial support from the Center of Innovation (COI) Program from Japan Science and Technology Agency (JST).

Open Access This article is licensed under a Creative Commons Attribution 4.0 International License, which permits use, sharing, adaptation, distribution and reproduction in any medium or format, as long as you give appropriate credit to the original author(s) and the source, provide a link to the Creative Commons licence, and indicate if changes were made. The images or other third party material in this article are included in the article's Creative Commons licence, unless indicated otherwise in a credit line to the material. If material is not included in the article's Creative Commons licence and your intended use is not permitted by statutory regulation or exceeds the permitted use, you will need to obtain permission directly from the copyright holder. To view a copy of this licence, visit http://creativecommons. org/licenses/by/4.0/.

\section{References}

Arias AC, MacKenzie JD, McCulloch I et al (2010) Materials and applications for large area electronics: solution-based approaches. Chem Rev 110:3-24. https://doi.org/10.1021/ cr900150b

Chou SY, Krauss PR, Renstrom PJ (1995) Imprint of sub-25 nm vias and trenches in polymers. Appl Phys Lett 67:3114-3116. https:// doi.org/10.1063/1.114851

Faddoul R, Reverdy-bruas N, Blayo A (2012) Formulation and screen printing of water based conductive flake silver pastes.pdf. Mater Sci Eng B Solid State Mater Adv Technol 177:1053-1066

Hendriks CE, Smith PJ, Perelaer J et al (2008) "Invisible" silver tracks produced by combining hot-embossing and inkjet printing. Adv Funct Mater 18:1031-1038. https://doi.org/10.1002/ adfm. 200601062

Hernández JJ, Monclús MA, Navarro-Baena I et al (2017) Multifunctional nano-engineered polymer surfaces with enhanced mechanical resistance and superhydrophobicity. Sci Rep 7:1-10. https://doi.org/10.1038/srep43450

Jiang JS, Liang JE, Yi HL et al (2016) Performances of screenprinting silver thick films: rheology, morphology, mechanical and electronic properties. Mater Chem Phys 176:96-103. https:// doi.org/10.1016/j.matchemphys.2016.03.032

Kang BJ, Lee CK, Oh JH (2012) All-inkjet-printed electrical components and circuit fabrication on a plastic substrate. Microelectron Eng 97:251-254. https://doi.org/10.1016/j.mee. 2012.03.032

Kawahara J, Andersson Ersman P, Nilsson D et al (2013) Flexible active matrix addressed displays manufactured by printing and coating techniques. J Polym Sci Part B Polym Phys 51:265-271. https://doi.org/10.1002/polb.23213

Kawase T, Shimoda T, Newsome C et al (2003) Inkjet printing of polymer thin film transistors. Thin Solid Films 438-439:279-287. https://doi.org/10.1016/S0040-6090(03)00801-0

Lee C, Kang BJ, Oh JH (2016) High-resolution conductive patterns fabricated by inkjet printing and spin coating on wettabilitycontrolled surfaces. Thin Solid Films 616:238-246. https://doi. org/10.1016/j.tsf.2016.08.027

Leenen MAM, Arning V, Thiem H et al (2009) Printable electronics: flexibility for the future. Phys Status Solid Appl Mater Sci 206:588-597. https://doi.org/10.1002/pssa.200824428

Michel B, Bernard A, Bietsch A et al (2001) Printing meets lithography: soft approaches to high-resolution patterning. IBM J Res Dev 45:697-719. https://doi.org/10.1147/rd.455.0697

Muanchan P, Suzuki S, Kyotani T, Ito H (2017) One-dimensional polymer nanofiber arrays with high aspect ratio obtained by thermal nanoimprint method. Polym Eng Sci 57:214-223. https://doi.org/10.1002/pen.24403

Sele CW, Von Werne T, Friend RH, Sirringhaus H (2005) Lithography-free, self-aligned inkjet printing with sub-hundrednanometer resolution. Adv Mater 17:997-1001. https://doi.org/ 10.1002/adma.200401285

Sirringhaus H, Kawase T, Friend RH et al (2000) High-resolution inkjet printing of all-polymer transistor circuits. Science 290(80):2123-2126. https://doi.org/10.1126/science.290.5499. 2123

Wang J, Ye H, Jiang Z et al (2004) Determination of diethylstilbestrol by enhancement of luminol-hydrogen peroxide-tetrasulfonated cobalt phthalocyanine chemiluminescence. Anal Chim Acta 508:171-176. https://doi.org/10.1016/j.aca.2003.12.003

Publisher's Note Springer Nature remains neutral with regard to jurisdictional claims in published maps and institutional affiliations. 